\title{
Advantages and limits of a price indexing system tying piglet prices to those of fattening pigs
}

\author{
Charles BRETTE \\ Institut National Agronomique Paris-Grignon \\ Centre d'Etude et de Recherche sur l'Économie \\ et l'Organisation des Productions Animales (C.E.R.E.O.P.A.)
}

By indexing piglet prices on those of fattening pigs, the magnitude of cyclic variations of piglet prices can be substantially reduced. Although the application of a constant coefficient which should not fall below Iog per cent as compared to the reference period of $1972-76$, reduces the variation gap of piglet prices considerably, the method of a fixed indexing is rather rigid.

Other indexing methods can reduce simultaneously the variation gap of piglet prices and that of the difference between the selling price of fattening pigs and the purchase price of piglets. Consequently, these methods would lead to a fair income distribution between pig rearers and feeders. In any case, it seems advisable to base the piglet price on the selling price of fattening pigs rather than on current prices of fattening pigs at the moment of piglet purchase.

\section{Economical and financial analysis of a sample of firms from the pork butchery and curing industry}

\author{
A. VIGNE \\ I.T.P., Service Économie, 34, bd de la Gare, 3 I50o Toulouse (France)
}

A group of twelve firms among the most important ones of the pork butchery and curing industry and representing about $4^{\circ}$ per cent of the gross turnover was studied on the basis of accountancy data obtained over a period of 3 years running from 1972 till 1974 .

As compared with the trading results of the whole agricultural and food industry, the pork butchery and curing industry, with a medium rate of added value, has to pay for a substantially higher proportion of man-power which set limits to the possibilities of investment and to the creation of reserves.

Another fact to be emphasized is the great sensitiveness of trading results towards the overall economic situation. The main raw material, the pig (about $70 \%$ of the turnover) is subjected to very high fluctuations of prices, which might reach 20 per cent and more from one year to another, whereas the selling prices fluctuate in a much slower way.

The lowering in the ratios of the overall economic yield and of the financial independence during the period studied clearly shows that the pig cycle might also seriously affect the output of the pig channel. 